\title{
Solar Photo-Voltaic Box Validation According to EURO Standards Using FEA
}

\author{
Ranjit Patil \\ HCL Technologies, Pune 411027, India
}

\begin{abstract}
The photo voltaic box is power conversion system. It ensures the protection of the maintenance people and installation against electrical faults. The below paper gives brief information on methodology to evaluate solar load, wind load, snow load, seismic load on photo voltaic box according to EURO standards.
\end{abstract}

Keywords: photo-voltaic box, Euro standards, solar and wind load

\section{Introduction}

The PV Box is a power conversion system. There may be a multitude of PV Box, according to equipment to put in the PV Box. It's possible to implant photovoltaic plants all over the world, that's why PV Box has to be calculated in consequence. We can encounter an infinity of climatic situations, which means an infinity of calculations. In this paper, we have finally chosen to calculate a unique configuration of PV Box. The PV Box which is the subject of this study is the results of a parametric study. This study has been realized in order to choose a representative situation of many cases that may be encountered in the world. Calculations are conducted with Euro codes. Followings regulations are used for calculations:

- Eurocode EN_1990 - : Basis of structural design

- Eurocode EN_1991-1-1: self weight

- Eurocode EN 1991-1-3: snow load

- Eurocode EN 1991-1-4 wind actions

- Eurocode EN_1998-1-4_Seismic action

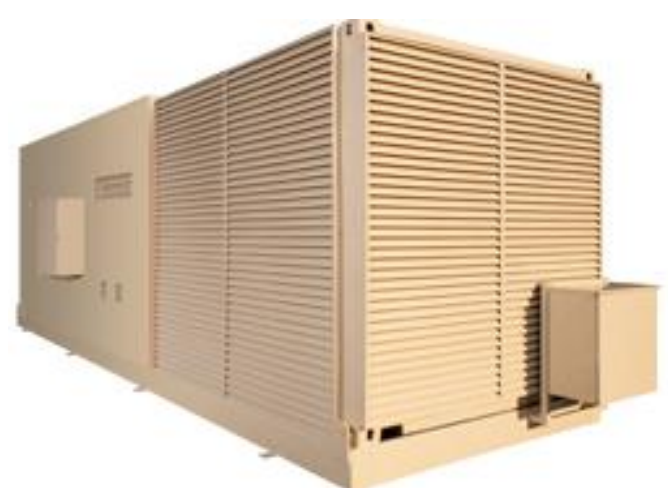

Figure 1: Solar PV Box

\section{Load Assumptions}

\subsection{Permanent loads}

This load takes account of the self weight of the structure plus $5 \%$ to take account of fixings weight, galvanization.

- The self-weight of the structure $+5 \%$ to take into account fastenings, galvanizing.

- The sandwich panels weight equal to $17 \mathrm{~kg} / \mathrm{m}^{2}$
- The 2 filtering boxes weights which are equal to $315 \mathrm{~kg}$ each.

- The 2 canopy weights which are equal to $45 \mathrm{~kg}$ each.

\subsection{Wind Loads}

Wind actions fluctuate with time and act directly as pressures on the external surfaces of enclosed structures and, because of porosity of the external surface, also act indirectly on the internal surfaces. They may also act directly on the internal surface of open structures. Pressures act on areas of the surface resulting in forces normal to the surface of the structure or of individual cladding components. Additionally, when large areas of structures are swept by the wind, friction forces acting tangentially to the surface may be significant. The wind action is represented by a simplified set of pressures or forces whose effects are equivalent to the extreme effects of the turbulent wind.

\subsection{Procedure to calculate Wind Loads according to Euro Standards:}

The fundamental value of the basic wind velocity, $v b, 0$, is the characteristic 10 minutes mean wind velocity, irrespective of wind direction and time of year, at $10 \mathrm{~m}$ above ground level in open country terrain with low vegetation such as grass and isolated obstacles with separations of at least 20 obstacle heights.

$$
\mathrm{Vb}=\text { Cdir } \times \text { Cseason } \times \mathrm{Vb}, 0
$$

From the basic wind velocity, calculate the mean wind velocity. For this, we have to consider terrain roughness and orography factor.

$$
\operatorname{Vm}(\mathrm{z})=\mathrm{Cr}(\mathrm{z}) \times \mathrm{Co}(\mathrm{Z}) \times \mathrm{Vb}
$$

$\operatorname{Cr}(\mathrm{z})$ is the roughness factor, $\operatorname{Co}(\mathrm{z})$ is the orography factor, taken as 1,0 .

$\mathrm{Cr}(\mathrm{z})$ depends on Terrain factor which can be evaluated as,

$$
\mathrm{Kr}=0.19 \times(Z 0 / Z 0, \text { II })^{0.07}
$$

$\mathrm{Kr}$ is the terrain factor.

Where, $\mathrm{Z}_{0}$ and $(\mathrm{Z} 0, \mathrm{II})$ are the terrain parameters, which depends on specific terrain regions.

$$
\text { Roughness factor }=\operatorname{Cr}(\mathrm{Z})=\mathrm{Kr} \times \operatorname{In}\left(Z^{Z} / Z_{o}\right)
$$

Turbulence Intensity: $\mathrm{I}_{\mathrm{v}}(\mathrm{z})=$ 


\section{International Journal of Science and Research (IJSR) \\ ISSN (Online): 2319-7064}

Index Copernicus Value (2013): 6.14 | Impact Factor (2014): 5.611

$$
\begin{array}{r}
I_{\mathrm{v}}(\mathrm{Z})=\frac{\sigma \mathrm{v}}{\operatorname{Vm}(\mathrm{z})}=\frac{\mathrm{Ki}}{\operatorname{Co}(\mathrm{z}) \cdot \operatorname{In}\left(\frac{\mathrm{z}}{\mathrm{zo}}\right)} \\
\text { for } Z_{\min } \leq \mathrm{Z} \leq \mathrm{Z}_{\max }
\end{array}
$$

Peak Velocity Pressure $=$ The peak velocity pressure $\mathrm{Qp}(\mathrm{z})$ at height $\mathrm{z}$, which includes mean and short-term velocity fluctuations.

$$
\mathrm{Q}_{\mathrm{p}}(\mathrm{z})=[1+7 \times \operatorname{Iv}(\mathrm{z})] \times 1 / 2 \times \rho \times \mathrm{V}^{2} \mathrm{~m}(\mathrm{z})=\mathrm{C}_{\mathrm{e}}(\mathrm{z}) \times \mathrm{Q}_{\mathrm{b}}
$$

The wind pressure acting on external surfaces can be calculated as

$$
\mathrm{We}=\mathrm{Qp} \times(\mathrm{Ze}) \times \mathrm{Cpe}
$$

Where, $\mathrm{Qp}(\mathrm{Ze})$ is peak velocity pressure, Ze is reference height for external pressure, $\mathrm{Cpe}$ is pressure coefficient for external pressure.

The wind pressure acting on the internal surfaces of a structure, Wi

$$
\mathrm{Wi}=\mathrm{Qp} \times(\mathrm{Zi}) \times \mathrm{Cpi}
$$

Where, Cpi is pressure coefficient for internal pressure.

According to Euro codes, the wind in direction should be studied in following cases.

1) Front to back

2) Back to front

3) Right to left.

4) Left to right.

As Solar PV box is symmetric for right to left case. So only Right to left case is studied.

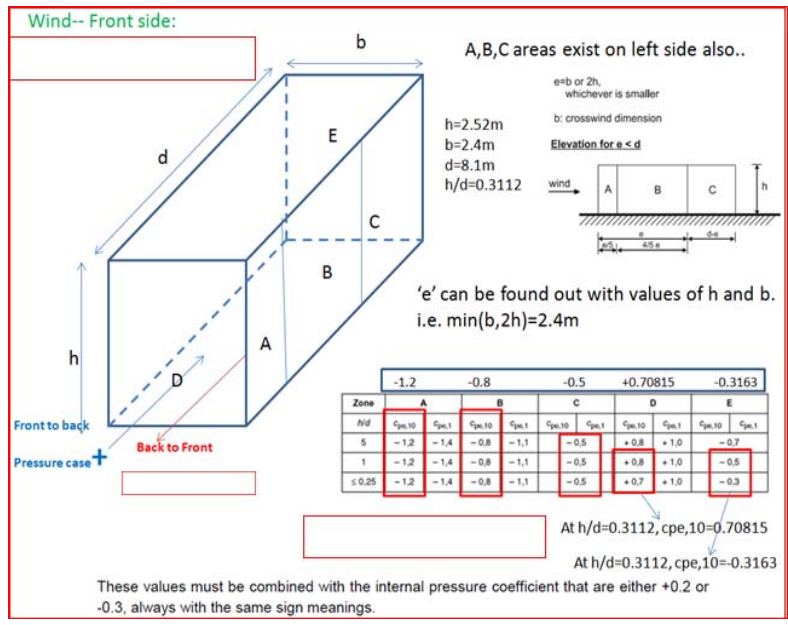

Figure 2: Determining pressure coefficients

For the internal pressure coefficient, the values for pressure coefficient considered as +0.2 or -0.3 always with same sign meaning when combined with external pressure coefficients. The wind force $\mathrm{Fw}$ acting on a structure or a structural component may be determined directly by using Expression,

$$
\mathrm{Fw}_{\mathrm{w}}=\mathrm{CsCd} \times \mathrm{Cf} \times \mathrm{Qp} \times(\mathrm{Ze}) \times \text { Aref }
$$

Where,

$\mathrm{CsCd}=$ Structural factor (For buildings with a height less than $15 \mathrm{~m}$ the value of $\mathrm{CsCd}$ may be taken as 1)

$\mathrm{Cf}$ is the force coefficient for the structure

$\mathrm{Qp}(\mathrm{Ze})$ is the peak velocity pressure

Aref is the reference area of the structure

\subsection{Snow Loads and combination of loads}

Snow load of $2.5 \mathrm{KN} / \mathrm{m} 2$ is assumed. Total top surface area for cabinet is about $19.44 \mathrm{~m} 2$

\section{Combinations of Loads:}

All combinations of Permanent action load, Primary action load, accompanying action load has to be considered. The design value $\mathrm{Fd}$ of an action $\mathrm{F}$ can be expressed in general terms as,

$$
\begin{aligned}
& \text { Fd }=\Upsilon f \times \text { Frep } \\
& \text { Frep }=\Psi \times \text { Fk }
\end{aligned}
$$

Where,

$\mathrm{Fk}$ is the characteristic value of the action.

Frep is the relevant representative value of the action.

$\Upsilon \mathrm{f}$ is a partial factor for the action which takes account of the possibility of unfavorable deviations of the action values from the representative values.

There will be two cases depending on whether Wind is primary or Snow is primary load. For permanent action (selfweight), for unfavorable case, multiplying factor of 1.1 is assumed. For primary actions, for unfavorable case, multiplying factor of 1.5 is assumed. For accompanying actions, when snow is accompanying action, partial factor of 1.5 and combination factor of 0.7 is assumed. For accompanying actions, when wind is accompanying action, partial factor of 1.5 and combination factor of 0.6 is assumed.

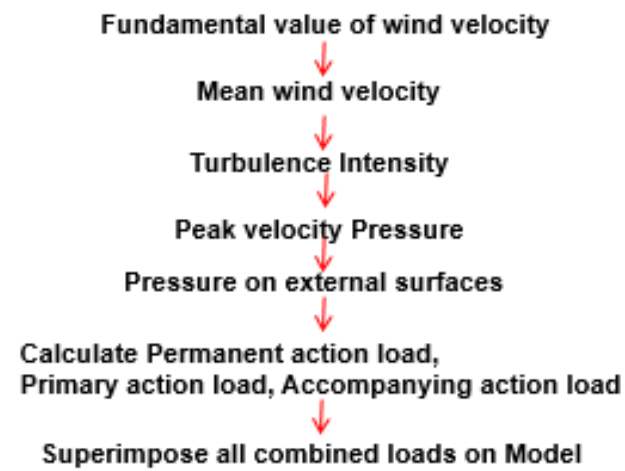

Figure 3: Flowchart for general procedure to calculate loads and combinations

\subsection{Seismic Analysis for Solar PV Box}

\section{Assumptions:}

No collapse approach is assumed for seismic analysis. Probability of exceedance is 50 years for this approach. Assumed Ground type : D , Deposits of loose-to-medium cohesion less soil (with or without some soft cohesive layers), or of predominantly soft-to-firm cohesive soil. Soil factor for D type is 1.8.Type 2 Spectra is assumed for horizontal loading. Design ground acceleration is assumed as 0.5 for vertical response spectrum we are going to use Type 1 Spectra. Behavior factor is assumed to be 1.5. 


\section{International Journal of Science and Research (IJSR) \\ ISSN (Online): 2319-7064 \\ Index Copernicus Value (2013): 6.14 | Impact Factor (2014): 5.611}

For the horizontal components of the seismic action the design spectrum, $\mathrm{Sd}(\mathrm{T})$, shall be defined by the following expressions:

$$
\begin{aligned}
& 0 \leq \mathrm{T} \leq \mathrm{T}_{\mathrm{B}}: \quad \mathrm{S}_{\mathrm{d}}(\mathrm{T})=\mathrm{a}_{\mathrm{g}} \times \mathrm{S} \times\left[\frac{2}{3}+\frac{T}{T B} \times\left(\frac{2.5}{q}-\frac{2}{3}\right)\right] \\
& \mathrm{TB} \leq \mathrm{T} \leq \mathrm{TC}: \quad \mathrm{Sd}(\mathrm{T})=\text { ag } \times \mathrm{S} \times \frac{2.5}{q} \\
& \mathrm{TC} \leq \mathrm{T} \leq \mathrm{TD}: \mathrm{Sd}(\mathrm{T})=\mathrm{ag} \times \mathrm{S} \times \frac{2.5}{q} \times\left[\frac{T C}{T}\right] \\
& \geq \beta \times \mathrm{ag} \\
& 2.5 \\
& \mathrm{TD} \leq \mathrm{T}: \mathrm{Sd}(\mathrm{T})=\text { ag } \times \mathrm{S} \times q \times[\mathrm{Tc} \times \mathrm{TD} / \mathrm{T} 2] \\
& \geq \beta \times \mathrm{ag}
\end{aligned}
$$

$\mathrm{T}$ is the vibration period of a linear single-degree-of-freedom system; ag is the design ground acceleration on type A ground ;

$\mathrm{T}_{\mathrm{B}}$ is the lower limit of the period of the constant spectral acceleration branch;

$\mathrm{T}_{\mathrm{C}}$ is the upper limit of the period of the constant spectral acceleration branch;

$T_{D}$ is the value defining the beginning of the constant displacement response range of the spectrum; $\mathrm{S}$ is the soil factor.

Table 1

\begin{tabular}{|l|l|l|l|l|}
\hline Spectrum & Avg/ag & TB(s) & TC(s) & TD(s) \\
\hline Type 1 & 0.9 & 0.05 & 0.15 & 1 \\
\hline Type 2 & 0.45 & 0.05 & 0.15 & 1 \\
\hline
\end{tabular}

For the vertical component of the seismic action the design spectrum is given by above expressions, with the design ground acceleration in the vertical direction, $\mathrm{a}_{\mathrm{vg}}$ replacing $\mathrm{a}_{\mathrm{g}}$, $\mathrm{S}$ taken as being equal to 1 .

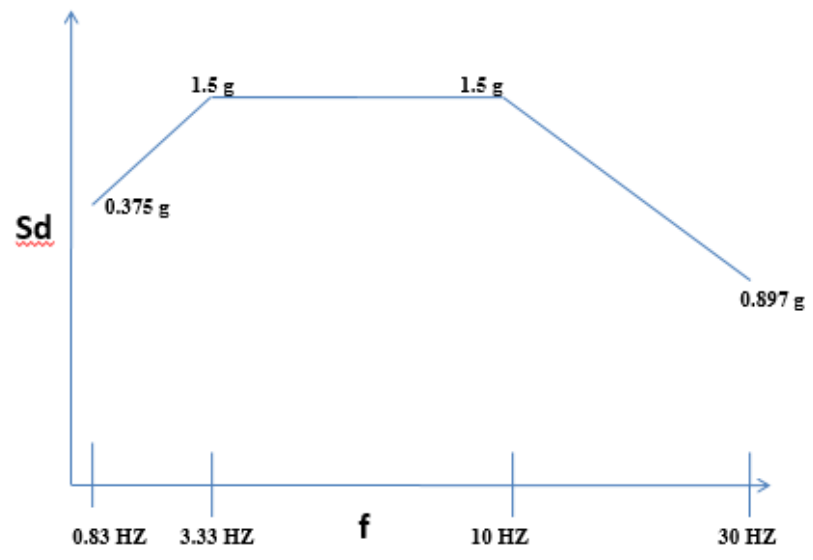

Figure 4: Horizontal Loading Spectrum

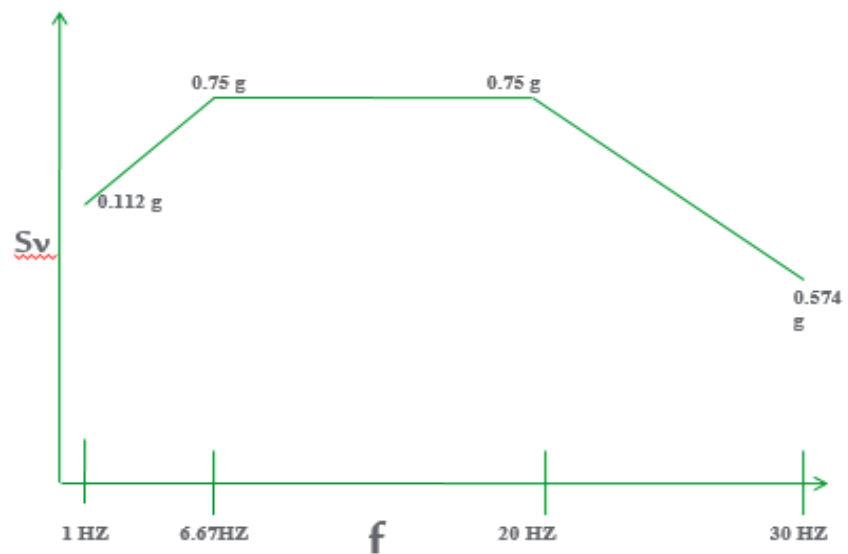

Figure 5: Vertical Loading Spectrum

\subsection{Combinations of the seismic action with other actions:}

The inertial effects of the design seismic action shall be evaluated by taking into account the presence of the masses associated with all gravity loads appearing in the following combination of actions: $\sum \mathrm{G} \mathrm{k,j}$ “+” $\sum \Psi \mathrm{E}, \mathrm{i} \times \mathrm{Q} \mathrm{k}, \mathrm{i}$

Where,

$\Psi$ E, $\mathrm{i}$ is the combination coefficient for variable action $\mathrm{i}$ $\sum \Psi \mathrm{E}, \mathrm{i}$ is the combination coefficients ( 0.2 for our case).

Superimposing of Permanent / Variable loading analysis and response spectrum is done in following ways.

1)Adding ( Max value of Von mises stress in Permanent action + variable action corresponding stress at same region in Response spectrum )

2)Adding ( $\max$ value of stress in Response spectrum + corresponding stress at same region in Permanent action loading + Variable action load)

3)Reducing the stress safety level by stress observed in other action.

\subsection{Boundary Conditions}

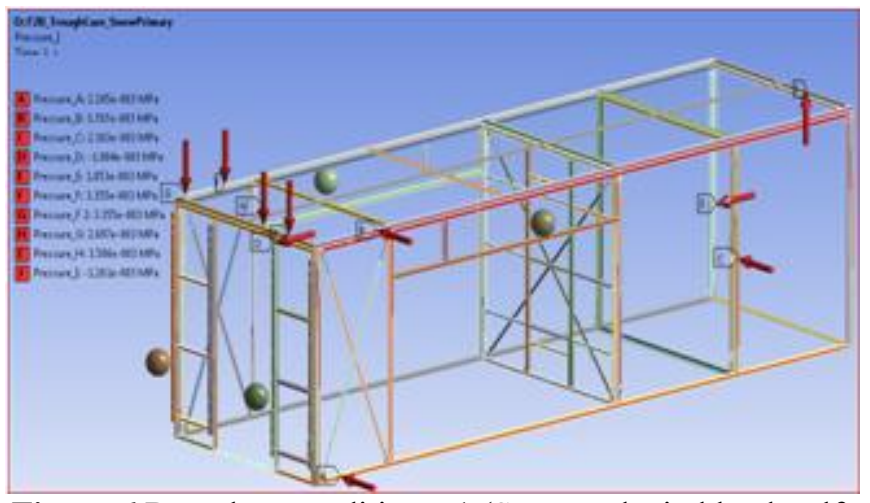

Figure 6 Boundary conditions -1 (Snow and wind load, selfweight) 


\section{International Journal of Science and Research (IJSR) \\ ISSN (Online): 2319-7064}

Index Copernicus Value (2013): 6.14 | Impact Factor (2014): 5.611

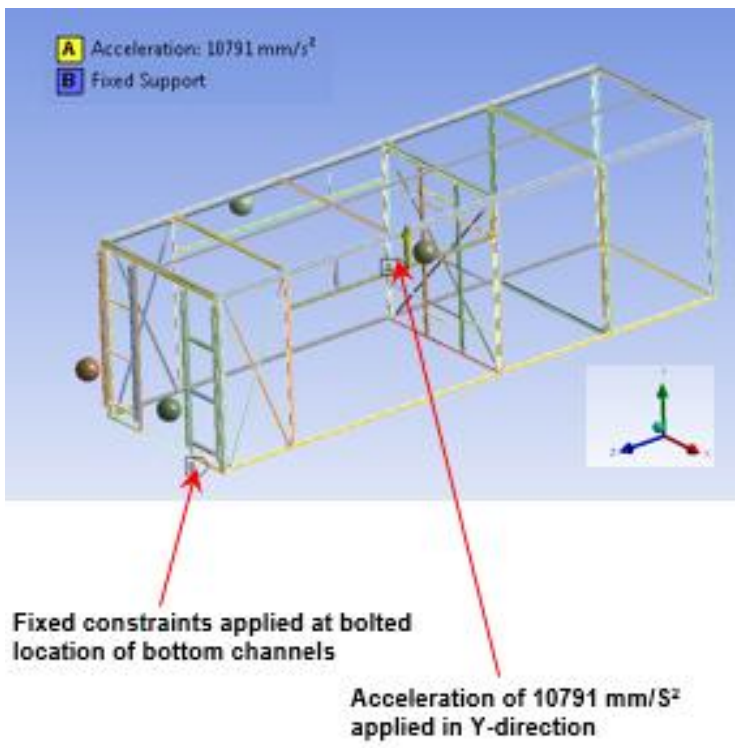

Figure 7: Boundary conditions -2 (Snow and wind load, self-weight )

Bottom of solar PV box is fixed at bolted locations. Wind loads and snow loads are applied on surfaces as pressure by calculating force values and corresponding surface areas values.

\section{Loading combination for $\mathrm{Z}$ direction loading : $0,30 E_{\mathrm{Edx}}$ "+" $0,30 E_{\mathrm{Edy}}$ "+" $E_{\mathrm{Ed} r}$}

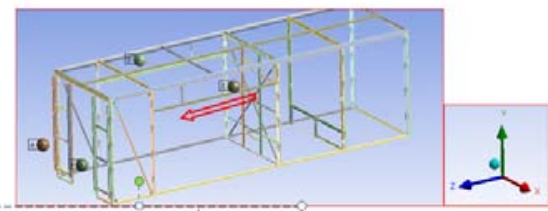

\section{Z-loading conditions}

\begin{tabular}{|c|c|c|c|c|}
\hline Frequency & $\begin{array}{c}\text { RS } \\
\text { Acceleration Z }\end{array}$ & $\begin{array}{c}\text { RS } \\
\text { Acceleration } x\end{array}$ & Frequency & $\begin{array}{c}\text { RS } \\
\text { Acceleration } Y\end{array}$ \\
\hline 0.83 & $0.375 \mathrm{~g}$ & $0.3 \times 0.375 \mathrm{~g}$ & 1 & $0.3 \times 0.112 g$ \\
\hline 3.33 & $1.5 \mathrm{~g}$ & $0.3 * 1.5 \mathrm{~g}$ & 6.67 & $0.3 * 075 \mathrm{~g}$ \\
\hline 10 & $15 \mathrm{~g}$ & $03 * 15 \mathrm{~g}$ & 20 & $0.3 \times 0.75 g$ \\
\hline 30 & $0.897 \mathrm{~g}$ & $0.3 \cdot 0.897 \mathrm{~g}$ & 30 & $0.3 \cdot 0.574 \mathrm{~g}$ \\
\hline
\end{tabular}

Figure 8: Boundary conditions (Seismic) Horizontal loading)

\subsection{Results and Iterations Summary}

1. Case: Front to Back loading with Snow primary load

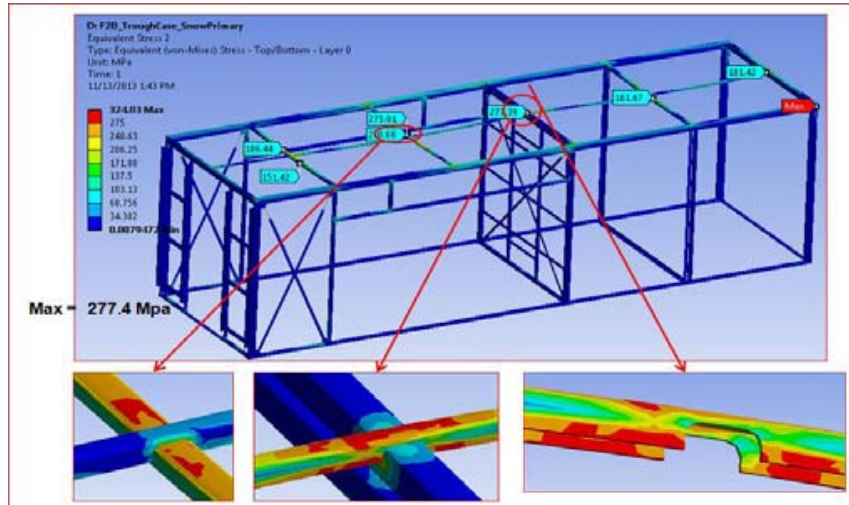

-Maximum stress value can be neglected as it is observed in small region -Red region shows Stress above the Yield value.

Figure 9: Results for base model
So it was clear that, Top channels need to be strengthened. New top channels with $50 * 50 \mathrm{~mm}$ cross section modified.

2. Case: Right to Left with Wind primary load.

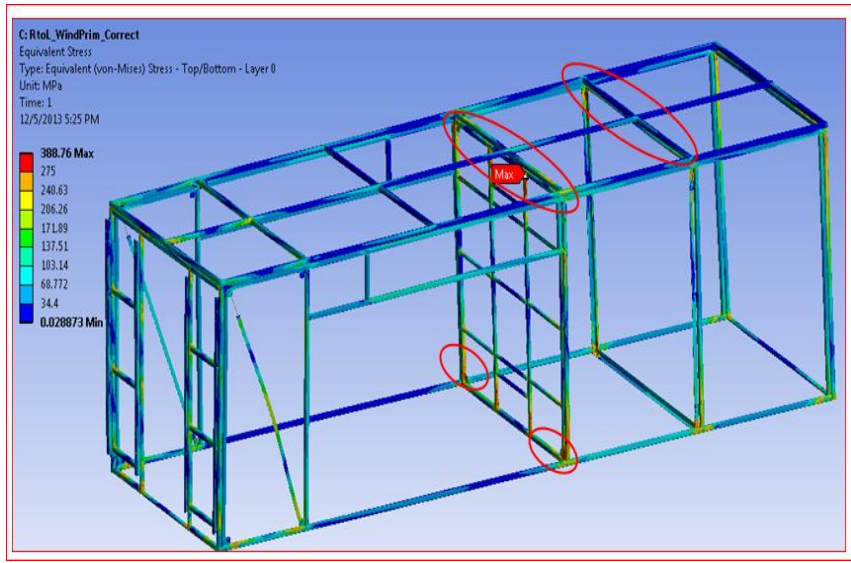

Figure 10: Results for Iteration 1

For right to left case with wind as primary load, it can be seen that stresses in middle bracket are going above yield limit. As stiffness in $\mathrm{x}$ direction for whole structure is less, we can expect more stresses for right to left loading. Also from modal results, initial $6^{\text {th }}$ mode is dominated in $x$ direction.

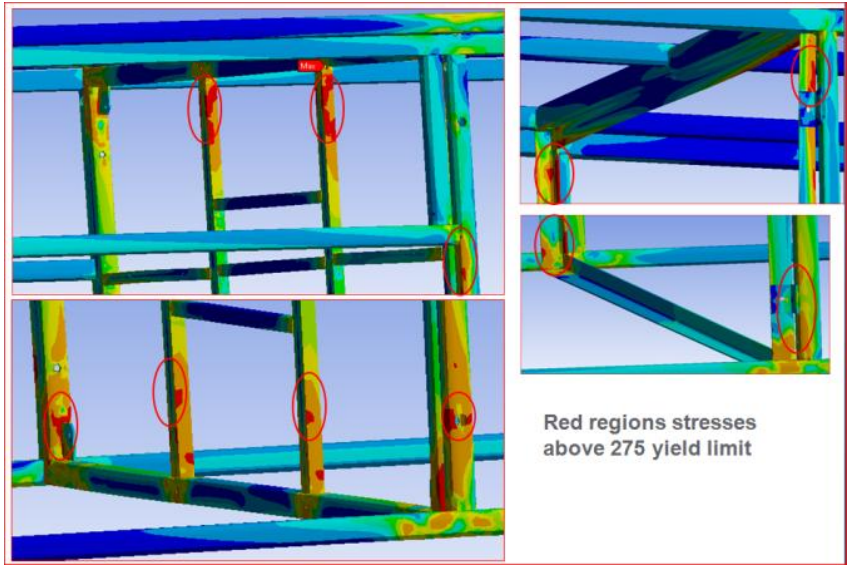

Figure 11: Results for Iteration model 1

Clearly can be seen, stresses are exceeding above yield limit. For right to left case, it was observed that stiffness in $\mathrm{X}$ direction for whole structure is low. So new middle wall is added to have more stiffness in $\mathrm{X}$ direction.

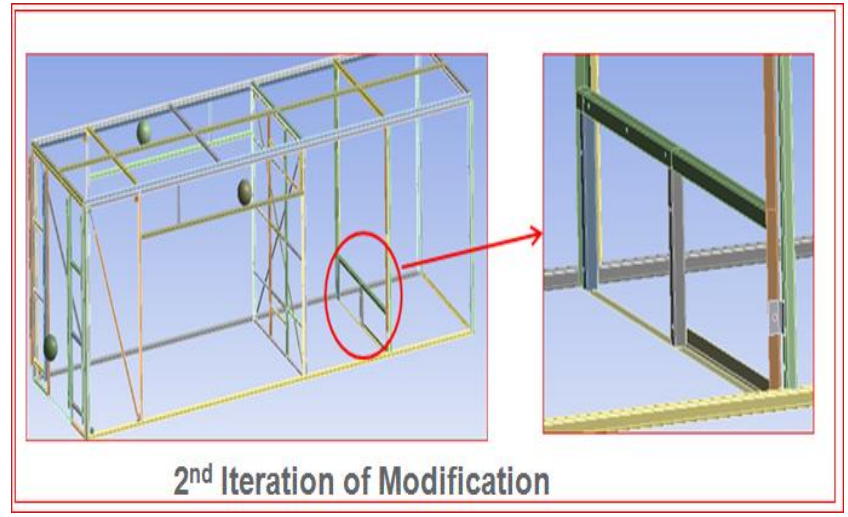

Figure 12: Iteration 2, modified with middle wall

Volume 4 Issue 11, November 2015 


\section{International Journal of Science and Research (IJSR) \\ ISSN (Online): 2319-7064}

Index Copernicus Value (2013): 6.14 | Impact Factor (2014): 5.611

After adding middle wall

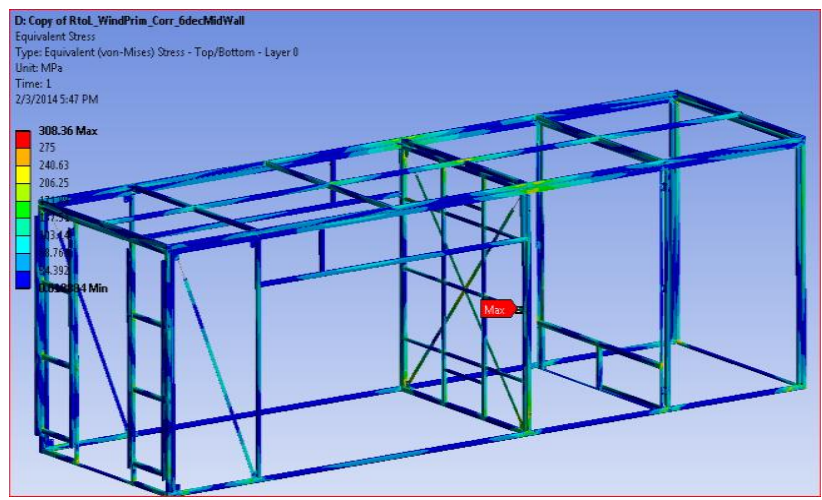

Figure 13: Results for Iteration model 2

With latest modified model, The stresses for all cases ( Right to Left, Front to Back, Back to Front ) with all load combinations; it seems the stresses generated for Solar PV box are within yield limit. So with modifications ( Increasing top channel dimensions to $50 \mathrm{~mm} \times 50 \mathrm{~mm}$, addition of middle wall to increase stiffness in $\mathrm{X}$ direction ) solar PV box is fulfilling static load criteria. So we can carry out seismic analysis for this final model.

\subsection{Seismic Analysis Results}

Modal results -
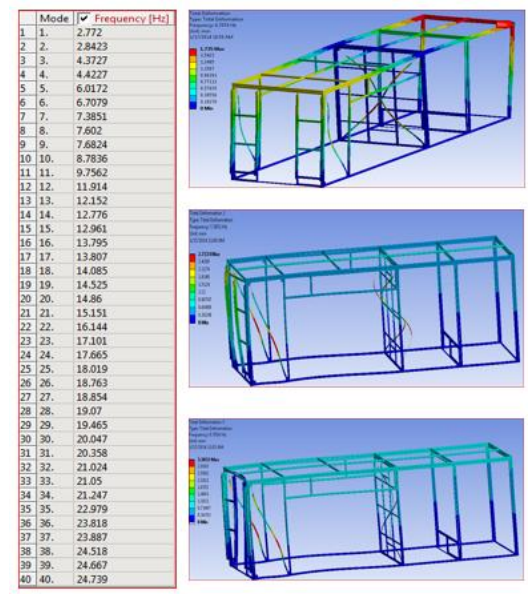

$6^{\text {th }}$ Mode $=6.7 \mathrm{~Hz}$ ( $X$ dominant $)$

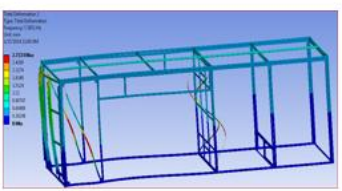

$7^{\text {th }}$ Mode $=7.38 \mathrm{~Hz}$ ( $Z$ dominant $)$

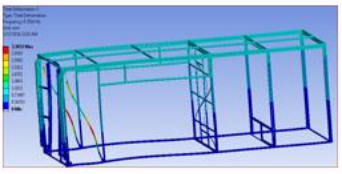

$10^{\text {th }}$ Model $=8.78 \mathrm{~Hz}$ ( $\mathrm{Z}$ dominant $)$

Figure 14: Modal analysis results

Case 1. Adding (Max value of Von mises stress in Permanent + Variable action with corresponding stress at same region in Response spectrum)
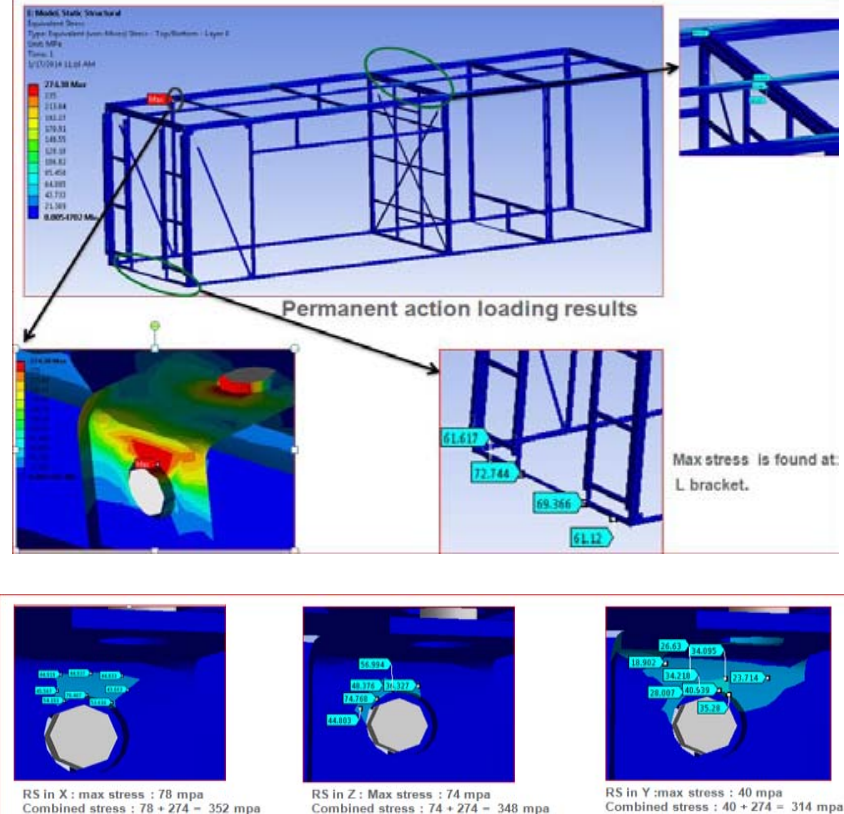

The max stress is not crossing the breaking limit of $410 \mathrm{mpa}$.

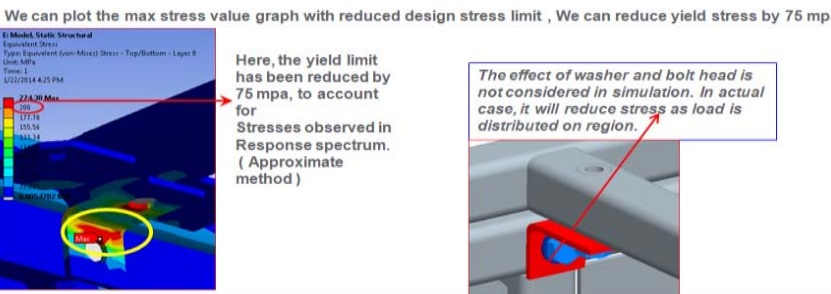

Figure 15: Seismic results case 1

Case 2: Adding ( Max value of stress in Response spectrum + corresponding stress at same region in Permanent + variable action).

Find out the location of max stress observed in Seismic analysis for $\mathrm{x}, \mathrm{y}, \mathrm{z}$ loading cases. Now for all 3 cases, add stress observed for Permanent + Variable action loading with maximum stress observed at seismic loading case.

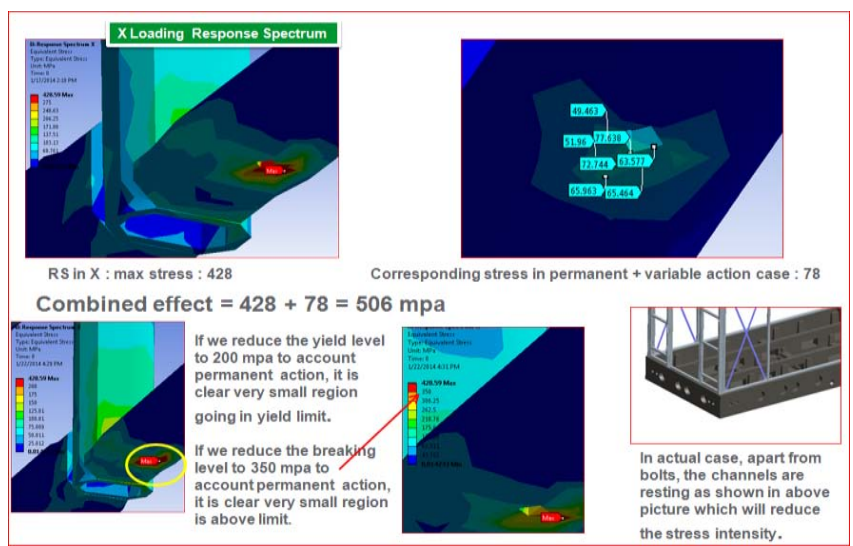

Figure 16: Seismic results case 2 : Response spectrum in $\mathrm{x}$ direction added with permanent and variable loading case 


\section{International Journal of Science and Research (IJSR) \\ ISSN (Online): 2319-7064}

Index Copernicus Value (2013): 6.14 $\mid$ Impact Factor (2014): 5.611

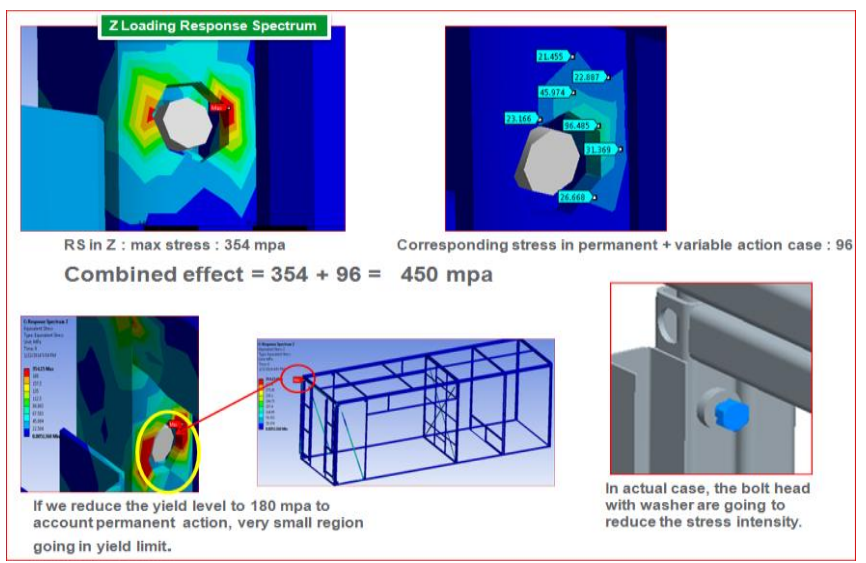

Figure 17: Seismic results case 2 : Response spectrum in $\mathrm{z}$ direction added with permanent and variable loading case

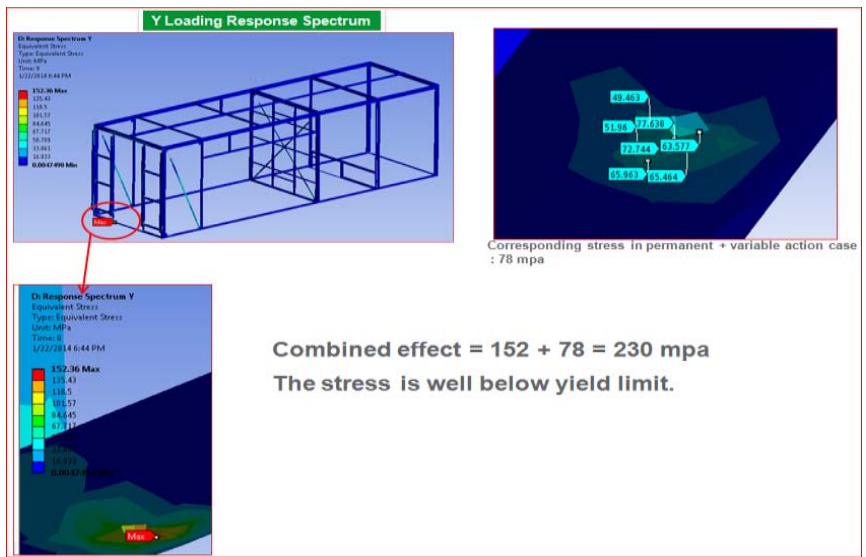

Figure 18: Seismic results case 2 : Response spectrum in y direction added with permanent and variable loading case

\section{Conclusion}

For Wind and Snow loading, it is clear that modified structure can withstand loads according to EURO standards. Initial results showed some parts were having stresses above yield limit but with modified parts ( Increased cross section of top channels $50 * 50 \mathrm{~mm}$ and addition of horizontal bottom channel ) solar PV box is safe. In Seismic case, the stresses are not severe for horizontal and vertical loading. Structure can sustain the loading as per EURO standards.

\section{References}

[1] https://law.resource.org/pub/eu/eurocode Eurocode EN_1990 - : Basis of structural design Eurocode EN_1991-1-1: self weight Eurocode EN_1991-1-3: snow load Eurocode EN_1991-1-4_wind actions Eurocode EN_1998-1-4_Seismic action

[2] Stephen Barkaszi, Colleen O'Brien,"Wind Load Calculations for PV Arrays" Solar American Board for Codes and Standards Report

[3] Solarworld "determining wind and snow loads for solar panels"

[4] Garrett H. Lyman, and Donald A. Bender, "Wind Load Determination for Residential Decks"

[5] Sayed Mahmoud1, Waleed Abdallah "Response Analysis of Multi-Storey RC Buildings under Equivalent
Static and Dynamic Loads According to Egyptian Code" International Journal of Civil and Structural Engineering Research ISSN 2348-7607 (Online) Vol. 2, Issue 1, pp: (79-88), Month: April 2014 - September 2014

[6] "Study of seismic and wind effect on multi storey RCC steel and composite building "Baldev D. Prajapatil \& D. R. Panchal, International Journal of Advances in Engineering \& Technology, Sept. 2013.

\section{Author Profile}

Ranjit Patil received the B.E. degrees in Mechanical Engineering from Shivaji university in 2002. He received M.Tech Degree in Machine design from IIT Roorkee in 2007. From last $8+$ years he is working in Industry as FEA analyst. 